\title{
A FORMA INSTITUCIONAL DA NEGAÇÃO: HEGEL, LIBERDADE E OS FUNDAMENTOS DO ESTADO MODERNO
}

\author{
Vladimir Safatle* \\ vsafatle@yahoo.com
}

RESUMO Trata-se de discutir as críticas a conceitos insuficientes de liberdade, tais como elas aparecem na Filosofia do direito, de Hegel. Com isto, espera-se expor os verdadeiros problemas que a teoria hegeliana do Estado procura resolver. Tais problemas permitem lançar novas luzes em alguns aspectos decisivos da teoria hegeliana do reconhecimento.

Palavras-chave liberdade, Estado, reconhecimento, jacobinismo, sociedade civil

ABSTRACT The aim of this article is to discuss the critiques of inadequate concepts of freedom, as we can find in Philosophy of Right, from Hegel. This discussion could help us to show the real problems that the Hegelian theory of State try to solve. It could help also to reconstruct some decisive aspects of Hegelian theory of recognition.

Keywords freedom, State, recognition, jacobinism, civil society

Para Marcos Muller, com gratidão e admiração.

* Professor livre-docente do Departamento de Filosofia da Universidade de São Paulo e bolsista de produtividade do CNPq. Artigo recebido em 20/3/2011 e aprovado em 11/5/2011.

KRITERION, Belo Horizonte, nº 125, Jun./2012, p. 149-178. 
Mesmo que Kant, o grande destruidor no reino do pensamento, exceda Maximilian Robespierre em terrorismo... Henrich Heine

\section{Direito e liberdade}

O terreno do direito é de maneira geral o espiritual e sua situação e ponto de partida preciso é a vontade que é livre; na medida em que a liberdade constitui sua substância e determinação, o sistema do direito é a liberdade efetivada que o mundo do espírito produz a partir de si próprio, como segunda natureza ${ }^{1}$.

Esta afirmação de Hegel soa, atualmente, ingênua. Nossa sensibilidade contemporânea está muito mais à vontade defendendo o direito como a face mais visível de um aparato disciplinar que reproduz condições materiais da vida em conformidade com os interesses dos poderes hegemônicos no interior do Estado. Ou seja, estamos mais à vontade para defender, por exemplo, afirmações como esta de Theodor Adorno:

O meio no qual o mal, em virtude de sua objetividade, alcança um ganho de causa e conquista para si a aparência do bem é, em larga medida, esse da legalidade, que certamente protege positivamente a reprodução da vida, mas em suas formas existentes; graças ao princípio destruidor da violência, ele traz a tona seu princípio destrutivo (...) que o singular receba tanta injustiça quando o antagonismo de interesses o impele à esfera jurídica, não é, como Hegel gostaria de dizer, sua culpa, como se ele fosse cego para reconhecer seus próprios interesses na norma jurídica objetiva e suas garantias, mas ela é, muito mais, culpa da própria esfera jurídica².

No entanto, seria o caso de explorar com mais calma esta ideia hegeliana segundo a qual o objeto do direito é a vontade livre, sendo que o ordenamento jurídico não poderia ser outra coisa que a liberdade efetivada, a segunda natureza espiritual que se transmuta em hábito institucionalizado do homem. O vocabulário da "segunda natureza" é uma maneira astuta de insistir, contra o contratualismo, na existência da liberdade como direito natural inalienável

1 HEGEL, G.W.F. ; Grundlinien der Philosophie des Rechts, Frankfurt : Suhrkamp, 1986, par. 4. As traduções aqui apresentadas vem, em grande parte, do trabalho de tradução de Marcos Müller.

2 ADORNO, Theodor; Negative Dialektik, Frankfurt: Suhrkamp, 1973, pp. 303-304. Notemos como esta afirmação parece desdobrar uma colocação que encontramos em $O$ mal estar na civilização, de Freud: "Grande parte das lutas da humanidade centralizam-se em torno da tarefa única de encontrar uma acomodação conveniente, ou seja, um compromisso (Ausgleich) que traga felicidade entre reivindicações individuais e culturais; e um problema que incide sobre o destino da humanidade é o de saber se tal compromisso pode ser alcançado através de uma formação determinada da civilização ou se o conflito é irreconciliável" (FREUD, Sigmund; Das Unbehagen in der Kultur, In: Gesammelte Werke, Frankfurt: Fischer, 1999, p. 455). 
e irrenunciável, mas como um direito natural fundado em uma "segunda natureza" fruto de um longo processo histórico, em uma naturalização de hábitos que tem peso irreversível.

Isto nos permite dizer que os conceitos decisivos na filosofia hegeliana do direito são "liberdade" e "vontade livre", já que definem o campo da racionalidade do direito. Trata-se, então, de demonstrar que a perspectiva hegeliana nos traz elaborações importantes a respeito da relação necessária entre reconhecimento da vontade livre e constituição moderna das instituições. Como devem ser pensadas as instituições para que elas sejam capazes de dar conta de demandas de reconhecimento depositadas no conceito de "liberdade"? É possível pensar a liberdade fora de alguma garantia de reconhecimento institucional? Questões que nos levam necessariamente a uma outra, esta sim uma questão central, a saber: o que devemos entender por "liberdade" neste contexto?

Antes de entrarmos diretamente nestas discussões, notemos a peculiaridade da compreensão do sentido da noção de "direito" para Hegel. Por "direito", Hegel entende algo a mais do que o ordenamento estatal de regulação da vida social. "Direito" são: "Todos aqueles pressupostos sociais que se mostraram necessários para a realização da 'vontade livre' de cada sujeito individual"3. Tais pressupostos sociais englobam o ordenamento jurídico atualmente existente com sua dinâmica conflitual interna, as instituições políticas que compõe o Estado moderno, as relações intersubjetivas de amor que se dão no interior da família, a disposição subjetiva formada a partir da internalização de preceitos morais, a dinâmica do livre-mercado, entre outros. Eles ainda devem estar, de uma certa forma, assegurados (ou em processo de garantia) no interior dos quadros atuais do Estado moderno.

De fato, aí está boa parte da complexidade da aposta hegeliana: este Estado não pode ser apenas um ideal, um dever ser. Se a função da filosofia do direito é: "apresentar e conceitualizar o Estado como em si racional" é porque ela deve ser capaz de apresentar, a partir de sua necessidade racional, o Estado que está em vias de se realizar como resultado do projeto moderno. Ou seja, não se trata nem do Estado atualmente realizado, nem de um Estado ideal, simples ideia sem relação alguma com a efetividade atual. Trata-se de um Estado que pode potencialmente se realizar, isto no sentido de algo que explora os conflitos sociais atuais para se realizar.

Esta é uma maneira de lembrar que, afinal, um ordenamento jurídico estatal está longe de ser algo monolítico e organicamente coeso. Antes, ele é o 
resultado heteróclito da sedimentação de lutas sociais entre várias disposições contrárias e mesmo contraditórias no interior da sociedade. O ordenamento jurídico traz as marcas destas lutas e conflitos. Neste sentido, cabe à filosofia do direito apresentar quais lutas e conflitos definiram a tendência de racionalidade do ordenamento jurídico. Talvez seja por isto que Hegel precise terminar seu prefácio à Filosofia do direito com a bela metáfora da filosofia como a coruja de Minerva que levanta vôo apenas com a irrupção do crepúsculo. Pois a filosofia procura mostrar como os conflitos sociais que dão forma ao direito, que imprimem tendências no interior do direito, são mobilizações do Espírito na sua procura em realizar o conceito de liberdade no interior da vida social. Uma realização que nunca é linear, que nunca deixa de levar em conta dimensões táticas e estratégicas do pensamento, assim como a configuração de situações locais. Mas uma realização que, ao menos segundo Hegel, já teria sido capaz de deixar marcas irreversíveis em nosso ordenamento jurídico, principalmente depois do Código napoleônico e do impacto da Revolução Francesa.

Desta forma, por insistir que a vontade livre só pode ser pensada como efetivação de pressupostos que devem estar em processo de institucionalização na vida social, Hegel precisa fazer a crítica de dois modelos hegemônicos de liberdade: um baseado na hipóstase das exigências de autenticidade e outro baseado na hipóstase das exigências de autonomia. A hipóstase destes dois modelos nos leva à perpetuação da contradição entre liberdade e instituição, contradição inaceitável para Hegel. Pois a autenticidade, quando hipostasiada, só poderia produzir uma noção de liberdade negativa que, quando utilizada como guia para a ação política, nos leva diretamente ao terror. Já a autonomia, quando hipostasiada, produz uma noção de livre-arbitrio que, ao servir de guia para a ação política, acaba por levar a uma profunda atomização social produzida pela elevação da categoria de "indivíduo" a elemento central da vida social. Vejamos cada uma destas distorções do conceito de liberdade, que não deixam de tecer relações entre si. Ao fim, poderemos compreender melhor qual é a especificidade do conceito hegeliano.

\section{Da liberdade negativa ao terror}

Se se contrapõe ao direito positivo e às leis o sentimento do coração, a inclinação e o arbítrio (Willkür), não pode ser a Filosofia, pelo menos, que reconhece tais autoridades. - $\mathrm{O}$ fato de que a violência e a tirania possam ser um elemento do direito positivo lhe é contingente e não concerne à sua natureza ${ }^{5}$. 
Tal frase é decisiva. Hegel está a lembrar, entre outras coisas, que a liberdade não pode ser confundida com a presumida autenticidade da espontaneidade imediata dos sentimentos. Uma autenticidade que veria, nas leis, apenas a coerção e a violência institucionalizada sob a forma do direito positivo, já que as leis nunca seriam condizentes com aquilo que Hegel chamou, na Fenomenologia do Espírito, de "as leis do coração". Leis estas para as quais o curso do mundo é necessariamente pervertido. Contra tal hipóstase da autenticidade, para a qual todo direito é apenas uma forma velada de violência, Hegel quer defender afirmações como: "A liberdade é apenas isto, conhecer e querer tais objetos substanciais universais como o direito e a Lei e produzir uma realidade (Wirklichkeit) que lhes é conforme : o Estado"6.

Uma afirmação desta natureza é facilmente objeto das piores confusões. "Livre é a vontade que deseja a Lei": não é difícil ouvir, nesta frase orwelliana, a confissão de uma filosofia que parece não compreender o sentido de experiências, tão comuns em nossas sociedades, de dissociação entre direito e justiça. Pois o que dizer quando estamos diante de leis injustas? E, principalmente, por que falar isto em um momento no qual o estado prussiano estava animado pelo ímpeto do Congresso de Viena (1814-1815) e pela Restauração anti-liberal que visava aplacar de vez a influência dos ideais da Revolução Francesa? Lembremos como não foram poucos aqueles que viram, na Filosofia do direito, a prova maior da adesão de Hegel à Restauração (exemplo maior aqui é o livro de Rudolf Haym, Hegel e seu tempo).

No entanto, devemos salientar um ponto fundamental. Não houve filósofo de seu tempo mais claramente comprometido em elevar a Revolução Francesa a acontecimento decisivo da modernidade do que Hegel ${ }^{7}$. Como disse um bom comentador, Domenico Losurdo: "Não existe revolução na história da humanidade que não tenha sido apoiada e celebrada por esse filósofo que também tem fama de ser um incurável homem da ordem"», seja a revolução americana, seja a revolução haitiana de Toussaint L'ouverture, as revoltas da plebe contra os patrícios, a rebelião dos escravos sob o comando de Spartacus, a revolta camponesa na época da reforma ou ainda a revolução francesa. Sobre esta última, basta lembrarmos da maneira como ela é descrita nas Lições sobre a filosofia da história :

Mas é apenas agora que o homem veio a reconhecer que o pensamento deve reger a realidade espiritual. Isto foi um colossal raiar do Sol. Todos os seres pensantes

6 HEGEL, Vorlesungen über die Philosophie der Geschichte, Frankfurt : Suhrkamp, 1986, p. 82

7 Ver, a este respeito, RITTER, Joachim; Hegel et la révolution française, Paris : Beauchesne, 1970.

8 LOSURDO, Domenico, Hegel, Marx e a tradição liberal, São Paulo : Unesp, 1997, p. 155 
celebraram esta época. Uma emoção sublime comandou este tempo, o mundo viu um entusiasmo do Espírito, como se a reconciliação efetiva entre o divino e o mundo apenas agora chegasse ${ }^{9}$.

Mas Hegel saberá ter palavras duras contra o jacobinismo e o terror revolucionário. De fato: "a experiência do terror jacobino é criticada politicamente, em termos bastante severos, mas jamais é demonizada e reduzida a uma simples orgia de sangue (...) O líder jacobino não era a besta sanguinária da qual falava certamente o publicismo da Restauração, mas, muitas vezes, também os publicistas liberais" ". Hegel sabe que o terror é o resultado desastroso da primeira manifestação de um conceito de liberdade que tem no seu bojo o momento da liberdade negativa enunciada em nome da autenticidade entusiasmada do sentimento. Ele é a "liberdade absoluta" transformada em fúria da destruição, pois liberdade que não reconhece nenhuma possibilidade de sua institucionalização, que vê todo direito como perda da espontaneidade livre do entusiasmo revolucionário e que, por isto, se volta contra tudo que procura determiná-la, contra todo governo. Como Hegel dirá na Fenomenologia do Espírito, para esta liberdade absoluta: "O que se chama governo é apenas a facção vitoriosa, e no fato mesmo de ser facção, reside a necessidade de sua queda, ou inversamente, o fato de ser governo o torna facção e culpado" ". Afinal, o terror jacobino nada tem a ver com a simples violência totalitária do Estado contra setores descontentes da sociedade civil. Na verdade, ele foi o movimento autofágico de destruição da sociedade e de auto-destruição do Estado, isto até o momento em que os próprios líderes jacobinos terminaram na guilhotina. $\mathrm{O}$ jacobinismo é a figura reflexiva do terror que se volta contra si mesmo ${ }^{12}$.

No entanto, e isto se esquece muitas vezes, Hegel não deixa de salientar que tal momento negativo da liberdade é um momento necessário da história do Espírito. Para compreender isto, devemos definir melhor o que Hegel

9 HEGEL, ibidem, p. 529

10 LOSURDO, ibidem, p. 162

11 HEGEL, Fenomenologia do Espírito, vol II, Petrópolis: Vozes, 1991, p. 97. Como dirá Charles Taylor: "a maldição da vacuidade assombra também este projeto. Sua meta não é fundar a sociedade em nenhum interesse particular ou princípio positivo tradicional, mas fundá-la somente na liberdade. Isso, porém, sendo vazio, não proporciona uma base para uma nova estrutura articulada da sociedade. Apenas prescreve à destruição das articulações existentes e de quaisquer novas articulações que ameacem surgir" (TAYLOR, Charles; Hegel e a sociedade moderna, Belo Horizonte: Loyola, 2005, p. 103)

12 Neste sentido, ele se difere de outra figura do terror revolucionário: o stalinismo. Aqui, temos a constituição de um aparelho de violência estatal legitimado pela violência revolucionário e que se volta, de forma constante, contra a sociedade e setores do próprio Estado. No entanto, ele garante a perpetuação de um núcleo dirigente sustentado pela figura de um déspota, o que não é o caso no jacobinismo. 
entende por "liberdade negativa". No parágrafo 5 da sua Filosofia do direito, Hegel faz a seguinte afirmação:

A vontade contém $\alpha$ ) o elemento da pura indeterminidade ou da pura reflexão do eu dentro de si, na qual estão dissolvidas toda restrição, todo conteúdo imediatamente aí-presente pela natureza, pelas carências, pelos desejos e impulsos, ou dados e determinados pelo que quer que seja; a infinitude irrestrita da abstração absoluta ou universalidade, o puro pensamento de si mesmo ${ }^{13}$.

A noção de "liberdade negativa", enquanto primeiro momento da vontade, aparece pois como possibilidade de me liberar de toda determinidade, ser absolutamente para si, como vemos no famoso início da dialética do Senhor e do Escravo. Daí a noção de "abstração absoluta", noção que indica a posição de uma incondicionalidade que aparece como a primeira manifestação da universalidade. Incondicionalidade que, por sua vez, procura a todo momento reafirmar sua inadequação às determinações postas. Um pouco como se o jacobinismo fosse a realização política de um desejo pensado como pura negatividade. Por isto, a hipóstase desse momento negativo da liberdade é descrito por Hegel em termos bastantes duros:

É a liberdade do vazio, que, erigida em figura efetiva ou em paixão, e permanecendo meramente teórica, torna-se, no domínio religioso, o fanatismo da contemplação pura dos hindus, mas, volvendo-se para a efetividade, torna-se, no domínio político, assim como no religioso, o fanatismo do destroçamento de toda ordem social subsistente, e a eliminação dos indivíduos suspeitos a uma determinada ordem, assim como, o aniquilamento de toda organização que queira novamente vir à tona. Somente quando ela destrói algo é que esta vontade negativa tem o sentimento de sua existência.

No entanto, e este ponto deve ser salientado, Hegel lembra que é exclusivo do querer humano esta capacidade de abstrair-se de tudo, de transcender toda determinação posta. Por isto, ele deve insistir que :

Esta liberdade negativa ou esta liberdade do entendimento é unilateral, mas esta unilateralidade sempre contém em si uma determinação essencial: portanto, não é de se rejeitá-la, mas a deficiência do entendimento está em que ele ergue uma determinação unilateral à condição de única e suprema ${ }^{14}$.

13 HEGEL, Grundlilien ..., par. 5

14 Não deixa de ser provido de interesse lembrar que a compreensão de que a liberdade moderna exige um momento de liberdade negativa pode ser encontrada já em Descartes, ao menos se nos fiarmos em Sartre. Como ele mesmo dirá, a respeito da transcendência cartesiana: "Reconhecemos neste poder de escapar, de se mover, de se retirar para trás, uma prefiguração da negatividade hegeliana. A dúvida alcança todas as proposições que afirmam algo fora de nosso pensamento, ou seja, posso colocar todos os existentes em parênteses, estou em pleno exercício de minha liberdade quando, eu mesmo vazio e 
Devemos recompor o contexto histórico que leva Hegel a ver, nesta liberdade negativa, uma determinação essencial. Lembremos como Hegel compreende a modernidade como o momento histórico no qual o espírito "perdeu" a imediatez da sua vida substancial, ou seja, nada lhe aparece mais como substancialmente fundamentado em um poder capaz de unificar as várias esferas sociais de valores. Daí diagnósticos clássicos de época como:

[Nos tempos modernos] Não somente está perdida para ele [o Espírito] sua vida essencial; está também consciente dessa perda e da finitude que é seu conteúdo. [Como o filho pródigo], rejeitando os restos da comida, confessando sua abjeção e maldizendo-a, o espírito agora exige da filosofia não tanto o saber do que ele é, quanto resgatar por meio dela, aquela substancialidade e densidade do ser [que tinha perdido $]^{15}$.

Ou seja, a modernidade aparece aqui como época na qual a liberdade levou à perda dos vínculos substanciais com formas partilhadas de vida. Daí a ideia de que ela produziria um tipo de sentimento onde a experiência subjetiva da indeterminação aparece como saldo dos processos de socialização. Décadas depois de Hegel, a sociologia de Durkheim e Max Weber constituirão quadros convergentes de caracterização da modernidade como era própria a um certo sentimento subjetivo de indeterminação resultante da perda de horizontes estáveis de socialização. A autonomização das esferas sociais de valores na vida moderna, assim como a erosão da autoridade tradicional sedimentada em costumes e hábitos ritualizados, teria produzido uma perda de referências nos modos de estruturação das relações a si, uma problematização sem volta da espontaneidade de sujeitos agentes ${ }^{16}$. A partir de então, o sujeito só pode aparecer como:

esta noite, este nada vazio que contém tudo na simplicidade desta noite, uma riqueza de representações, de imagens infinitamente múltiplas, nenhuma das quais lhe vem precisamente ao espírito, ou que não existem como efetivamente presentes (...) É esta

nada, nadifico tudo o que existe" (SARTRE, Jean-Paul; Situations philosophiques, Paris: Gallimard, 1990, pp. 71-72)

15 HEGEL, Fenomenologia do Espírito, op. cit., p. 24

$16 \mathrm{E}$ não é por acaso que todos os dois pensem tais fenômenos através da modificação do sentido sociológico da confrontação com a morte. A este respeito basta lembrar de Max Weber, para quem: "a vida individual do homem civilizado, colocada dentro de um progresso infinito, segundo seu próprio sentido imanente, jamais deveria chegar ao fim; pois há sempre um passo à frente do lugar onde estamos, na marcha do progresso. E nenhum homem que morre alcança o cume que está no infinito. Abraão, ou algum camponês do passado, morreu 'velho e saciado de vida', por que estava no ciclo orgânico da vida (...) O homem civilizado, colocado no meio do enriquecimento continuado da cultura pelas ideias, conhecimento e problemas, pode 'cansar-se da vida', mas não 'saciar-se dela'” (WEBER, Max; Ensaios de sociologia, 5 ed., São Paulo: LTC, 2002, p. 166) 
noite que descobrimos quando olhamos um homem nos olhos, uma noite que se torna terrível, é a noite do mundo que se avança diante de nós" ${ }^{17}$.

No entanto, Hegel não está disposto a se contentar com diagnósticos sócio-históricos. Ele quer fornecer o fundamento ontológico da situação histórica própria à modernidade, como se tal perda de horizontes estáveis não fosse apenas o resultado da contingência de processos históricos, mas fosse a realização de um destino marcado com a necessidade do que tem dignidade ontológica. Daí a ideia de que a liberdade negativa tem uma determinação essencial ${ }^{18}$.

De fato, Hegel reconhece que a pura indeterminação da vontade só pode nos levar a um impasse tanto existencial quanto político. Podemos dizer que nos dois casos, não se vai além de uma "estetização da violência", seja da violência contra si que se realiza na insatisfação absoluta, na inadequação recorrente de todo agir e julgar, seja da violência política contra toda e qualquer instituição. No entanto, um dos problemas maiores da modernidade, ao menos segundo Hegel, problema este que está na base da sua filosofia do direito, pode ser compreendido da seguinte forma: como viabilizar o reconhecimento institucional de sujeitos pensados enquanto modos singulares de confrontação com o que se oferece como indeterminado e negativo? Pois podemos inverter o diagnóstico de Durkheim e Weber afirmando não ser apenas a indeterminação que produz sofrimento social, mas também a incapacidade das estruturas institucionais e dos processos de interação social reconhecerem a realidade fundadora da indeterminação na condição existencial de todo e qualquer sujeito. Neste sentido, o impasse jacobino demonstra também, entre outras coisas, a incapacidade de constituição de uma estrutura institucional capaz de reconhecer tal realidade fundadora da indeterminação. É levando em conta esta via que talvez sejamos obrigados a admitir que: "o passado terrorista deve ser aceito como nosso, mesmo que - ou precisamente porque - ele seja rejeitado criticamente"19.

Sendo assim, tudo se passa como se fosse questão de pensar a política e a continuidade dos ideais da Revolução Francesa após o impasse jacobino. Como dirá Ritter: "A Revolução pôs o problema que a época deve resolver

17 HEGEL, Jenaer Philosophie der Geistes, Freiburg : Karl Alber Verlag, 1979, p. 13

18 Para uma discussão mais aprofundada a respeito deste ponto, tomo a liberdade remeter a SAFATLE, Vladimir; $O$ amor é mais frio que a morte: negatividade, infinitude e indeterminação na teoria hegeliana do desejo, In: Revista Kriterion, v. 117, janeiro/julho 2008, PP. 95-125

19 ZIZEK, Slavoj; Robespierre: virtude e terror, Rio de Janeiro: Jorge Zahar, 2008 
(...) este da realização política concreta da liberdade"20. E, para tanto, uma reconciliação possível entre liberdade e direito estatal deve ser posta como tarefa para o pensamento ${ }^{21}$.

Para não ter seu momento negativo hipostasiado, a liberdade deve ser capaz de determinar seus objetos no interior de uma vida social institucionalizada através de um Estado justo. Hegel tem a seu favor o fato do jacobinismo não ser apenas impulso negativo, mas também procura em definir as condições do pertencimento ao estado moderno a partir de exigências irrestritas de universalidade. Não é por outra razão que foi graças ao jacobinismo que ocorreu a inflexão igualitária da Declaração dos direitos do homem e do cidadão, de 1793, assim como a ampliação dos direitos do homem para as colônias e o fim da escravidão. Só a partir de tais exigências de universalidade concreta as bases igualitárias do Estado moderno puderam ser fundadas. Podemos dizer que, de uma certa forma, a enunciação da universalidade concreta só é possível após a experiência da negatividade, pois ela pressupõe uma capacidade de abstração e transcendência, uma indiferença às diferenças fundamental para a fundação da noção moderna de cidadão ${ }^{22}$.

Como veremos, esta é questão de difícil equação. Toda a complexidade vem do fato da liberdade dever ser capaz de determinar seus objetos no interior da vida social, de fazê-los reconhecer, mas sem simplesmente anular o momento negativo que é imanente ao conceito moderno de liberdade e que encontrou sua expressão inicial deformada no terror jacobino. Assim, de uma maneira bastante peculiar, o Estado que Hegel procura pensar é o Estado pós-

20 RITTER, Hegel et la révolution française, op. cit., p. 25

21 Sabemos como, na Fenomenologia, o momento do impasse jacobino é ultrapassado pela liberdade da autonomia da consciência moral. Marcos Muller nos fornece uma descrição precisa deste processo: "Mas tudo se passa como se a experiência da efetivação política da liberdade absoluta e a sua autodestruição no experimento jacobino de promover, a partir da igualdade política e através da virtude republicana, imposta despoticamente, a igualdade social, fosse, na progressão fenomenológica das figuras, a condição indispensável do pleno acesso do espírito à consciência da liberdade como sendo o seu princípio fundamental e a sua destinação última. Tudo se passa portanto, na ordem de apresentação (Darstellung), como se, antes que a liberdade possa se desdobrar na interioridade moral, nessa "inefetividade" que, assume, então, "o valor do verdadeiro" (323, § 595), fosse preciso que ela passasse pela tentativa da sua realização política e pela experiência do seu impasse e da sua autodestruição no Terror”. (MÜLLER, Marcos; A liberdade absoluta entre a crítica à representação e o terror, mimeo). Neste sentido, podemos dizer que, ao criticar também a autonomia da consciência moral na Filosofia do direito, tudo se passa como se Hegel recolocasse no âmbito político-institucional o problema do pleno acesso do espírito à consciência da liberdade.

22 Notemos um problema já indicado antes de nós. A “abstração” que encontra na Revolução Francesa seu solo pode se transformar em um destes "aspectos mórbidos de um estado de permanente descompromisso", como dizia Paulo Arantes, que tem na formação desterritoralizada do intelectual moderno uma de suas figuras fundamentais. A este respeito, ver os dois primeiros ensaios de ARANTES, Paulo; Ressentimento da dialética, São Paulo: Paz e Terra, 1996. Dar a tal força de abstração um território é, no fundo, o desafio do Estado hegeliano. 
revolucionário constitucional, Estado capaz de levar em conta as exigências de reconhecimento e de universalidade postas em circulação pela Revolução Francesa.

\section{O formalismo do livre-arbítrio}

Mas, por enquanto, voltemos às críticas feitas por Hegel a modelos hegemônicos de liberdade. Como foi dito anteriormente, Hegel também critica um modelo de liberdade que hipostasia a noção de autonomia. Quando hipostasiada, tal noção produz uma ideia de livre-arbitrio que, ao servir de guia para a ação política, acaba por levar a uma profunda atomização social resultante da elevação da categoria de "indivíduo" a elemento central da vida social. Tentemos entender melhor este ponto.

Sabemos como a noção moderna de autonomia nos aparece, normalmente, como a capacidade dos sujeitos porem para si mesmos a sua própria Lei moral, transformando-se assim em agentes morais capazes de se auto-gover$\operatorname{nar}^{23}$. Vinda de Rousseau, para quem : "a obediência à lei que uma pessoa prescreveu para si mesma é liberdade", esta noção de autonomia ganha, com Kant, contornos novos e decisivos.

Esta lei que os sujeitos prescrevem para si mesmos a fim de se afirmarem como autônomos não é, como sabemos, uma lei particular, ligada aos interesses egoístas da pessoa privada. Antes, ela é incondicional, categórica e universal. Lei capaz de abrir as portas para o reconhecimento de um campo intersubjetivo de validação da conduta racional e que levaria o sujeito a guiar suas ações em direção à realização de uma ligação sistemática dos diversos seres racionais por leis comuns. Para que ela tenha realidade, faz-se necessário então que os sujeitos tenham algo mais do que desejos particulares e "patológicos". Eles precisam ter uma vontade pura que age por amor à universalidade da Lei. Vontade que se coloca como dever. Pois, através do dever, a consciência pode dar para si mesma sua própria lei, julgar sua própria ação como quem se cinde entre uma consciência que age e uma consciência que julga. No entanto, lembrará Hegel, a perpetuação da moralidade sob a forma do dever só pode produzir um impasse. Pois: "A 'moral' não é uma confrontação perpétua entre o homem tal como ele 'é' e este mesmo homem tal qual ele 
'deve ser'”24. Tal confrontação, se perpetuada, só poderá nos levar à completa desarticulação da capacidade de agir.

Hegel insiste, em vários momentos, que a desarticulação da capacidade de agir presente em tal concepção de autonomia tem um nome: "formalismo". Neste contexto, formalismo significa que a fundamentação da ação moral através da pura forma do dever não é capaz de fornecer um procedimento seguro de decisão a respeito do conteúdo moral de minhas ações. "Fundamentação através da pura forma do dever" significa definir a natureza moral de minha ação basicamente através de sua conformidade a certos procedimentos formais enunciados em um imperativo categórico (procedimentos de universalização sem contradição, de incondicionalidade e de categoricidade). Hegel não acredita que a fundamentação transcendental de um princípio moral possa garantir a clarificação de seus modos de aplicação. Ao contrário, ele insiste a todo momento que uma definição meramente formal do dever cai, necessariamente, em uma tautologia, em uma "identidade sem conteúdo".

Podemos compreender este ponto da seguinte maneira: na verdade, o dever, embora sendo aparentemente formal, tem um "conteúdo", que é, no fundo, o nome hegeliano para "particularização de contextos de ação". Maneira de lembrar que a determinação do sentido da ação moral não é fruto exclusivo de considerações procedurais. Ela exige uma articulação complexa referente à atualização de contextos particulares de ação. Pois o dever aparece no interior de situações particulares de ação, situações nas quais tenho um conteúdo definido ("devo ou não roubar esta mercadoria se tenho fome e não tenho dinheiro", "devo ou não largar minha mulher por um outro amor"). Isto demonstra como o dever é atividade tendo em vista sua realização na exterioridade. Ele se curva ao cálculo de uma pragmática contextualizada e intersubjetivamente estruturada. Só a partir daí a atividade pode ser capaz de por para si mesma um fim. Isto explica a definição dada por Hegel de moralidade:

O conceito de moralidade é o relacionar-se interior da vontade a si mesma. Mas, aqui, não há somente uma vontade, senão que a objetivação tem simultaneamente dentro de si a determinação de que a vontade singular se supera na objetivação, e, portanto, precisamente com isso, ao eliminar-se a determinação da unilateralidade, são postas duas vontades e uma relação positiva das mesmas uma à outra ${ }^{25}$.

Ou seja, a moralidade só encontra seu fundamento quando é capaz de se colocar não como vontade individual, mas como vontade que traz em si 
mesmo a referencia à "vontade dos outros" (termo muito menos claro do que possa inicialmente parecer). Por isto, Hegel deve dizer que: "A ação contém as determinações indicadas: a) de ser sabida por mim na sua exterioridade como minha, b) de ser a relação essencial ao conceito como a um dever-ser e c) de ser a relação essencial à vontade dos outros".

Já ao discutir a estrutura da intencionalidade moral, Hegel insiste neste ponto. Tais discussões podem ser compreendidas da seguinte forma: a vontade subjetiva não é mera vontade, mas motivação para agir. A ação feita é necessariamente alteração (Veränderung) de uma existência previamente dada, alteração a respeito da qual sou responsável. No entanto, há alterações previsíveis e alterações imprevisíveis. Há consequências a respeito das quais eu poderia facilmente representar e outras não. Até onde vai então o limite de minha responsabilidade? Quem define o que é previsível e facilmente representável a partir da minha ação? Quais os elementos devem ser levados em conta em tal definição?

Desprezar completamente as consequências e só medir a natureza da ação a partir das consequências: estes são dois equívocos complementares. Mas para definir o que é necessário no interior das consequências da ação, preciso de uma representação geral do que se segue a partir de um determinado propósito. Isto implica reconhecer que meu propósito está ligado a consequências que não são simplesmente definidas por mim, mas seguirão necessariamente à ação. Ou seja, não quero apenas o propósito. Quando, agi eu queria as consequências. Esta era minha intenção. Hegel procura pois expor a intenção como capacidade de reconstrução da totalidade de relações esperadas por uma ação.

Neste sentido, a intenção é pensada por Hegel como o momento do reconhecimento de que minha interioridade é habitada por considerações intersubjetivas sobre as consequências de toda ação (daí o recurso à "vontade dos outros"). Para poder ser a capacidade de reconstrução de uma totalidade de relações, a intenção deve ser um "determinado tipo de saber prático" 26 . Pois uma intenção está sempre ligada a uma rede de estados intencionais socialmente definida. Por isto, Hegel fala aqui de "caráter universal" de "valor da ação". Esta intenção é, na verdade, o nome que Hegel fornece para uma disposição de conduta que é resultado direto da sedimentação de modelos sociais de julgamento. Isto explica porque a intenção deve vir acoplada à uma

26 SEARLE, John; Intencionalidade, São Paulo : Martins Fontes, 2002, p. 198. De fato, as considerações de Hegel sobre a intenção, tais como elas aparecem no capítulo da Filosofia do direito dedicado à moralidade não estão muito longe do que podemos encontrar em John Searle. 
reflexão sobre das Wohl, ou seja, o bem, no sentido do que pode satisfazer a vida material. Pois tais modelos sociais de julgamento são o resultado de um processo histórico de procura por modos de realização de formas de vida que tem peso normativo.

Isto talvez explique porque Hegel parece inclinado a assumir a perspectiva de uma moralidade das consequências capaz de, ao mesmo tempo, levar em conta o cálculo da intenção. Mesmo que a imputabilidade leve em conta a disposição intencional (o caso de Édipo é, para Hegel, exemplar), esta moralidade das consequências descentra a cena de fundamentação da significação da ação moral, levando-a em direção àquilo cujo resultado final não pode ser completamente antecipado pela consciência (embora a intencionalidade moral já se fundamente a partir de um cálculo das consequências), nem pode ser previamente garantido por estratégias transcendentais ${ }^{27}$.

Este é o pano de fundo para compreender porque Hegel insiste várias vezes que a vontade livre que delibera, não delibera sob a forma do arbítrio. Pois quem diz arbítrio, diz escolha tendo em vista o conteúdo mais adequado para a forma da vontade. Eu escolho entre possíveis que aparecem para mim como realizações possíveis da minha vontade. No entanto, isto pressupõe que a auto-determinação da forma da minha vontade livre não porta, em si, o conteúdo no qual ela se realiza, o modo de sua efetivação. Por isto, Hegel deve dizer : "visto que somente o elemento formal da autodeterminação livre é imanente ao arbítrio, e o outro elemento, em contrapartida, lhe é algo dado, o arbítrio, se é que ele deve ser a liberdade, pode com certeza ser chamado uma ilusão".

Ou seja, Hegel está a dizer que não há escolha no interior da vontade livre. "A natureza da liberdade não pode se vincular à questão da liberdade de escolha" 28 . Por mais que isto possa parecer contra-intuitivo, a liberdade não é uma questão de escolha individual e é extremamente sintomático que nossas discussões contemporâneas sobre liberdade estejam, em larga medida, focadas sob este aspecto. Elas normalmente são discussões que giram em torno da possibilidade ou não da existência de algo como o livre-arbítrio, como se estivéssemos à procura de uma espécie de decisão capaz de suspender toda e qualquer determinação causal exterior à própria espontaneidade da decisão

27 Esta moralidade das consequências pressuposta pela perspectiva hegeliana não deixa de tecer proximidades com aquilo que Bernard Williams um dia chamou de moral luck. Ver, a este respeito, WILLIAMS, Bernard; Moral luck, Cambridge University Press, 1991. Na verdade, procurei pensar os delineamentos deste tipo de moralidade das consequências em SAFATLE, Vladimir; O duplo fundamento insuficiente da ação moral, In: NOVAES, Adauto; A experiência do pensamento, Rio de Janeiro: Agir, 2010.

28 PIPPIN, Robert; Hegel's practical philosophy: rational agency as ethical life, Cambridge University Press, 2008, p. 39 
individual, decisão que não segue nenhuma autoridade externa, por isto autônoma ${ }^{29}$.

Neste sentido, cria-se rapidamente uma dicotomia onde a noção de causas exteriores desempenha o papel de pólo contrário à uma autonomia completamente internalista. Hegel aborda, muitas vezes, tal questão relativa às causas exteriores à ação autônoma através da dicotomia vontade/ impulso (Trieb). Ele poderia abordá-la também através da dicotomia subjetividade/ intersubjetividade. Mas Hegel assume a primeira possibilidade para mostrar que o formalismo do dever é, também, ignorância a respeito da maneira com que os impulsos fornecem o conteúdo (isto no sentido das motivações para agir) da vontade livre. Ignorância de que : "Nada de grande foi realizado sem paixão, e não pode ser realizado sem ela. É apenas uma moralidade morta e geralmente hipócrita que se bate contra a forma das paixões" ${ }^{30}$.

\section{Natureza humana como história dos desejos desejados}

Esta é uma dicotomia central se lembrarmos como a concepção moderna de liberdade parece profundamente marcada pela oposição entre natureza e liberdade, causalidade externa determinada pela normatividade vital e causalidade interna determinada em condições de autonomia. Partindo da naturalização desta dicotomia, cremos que a vontade meramente determinada pelos impulsos naturais só pode ser, pretensamente, completamente condicionada por aquilo que lhe é exterior. No entanto, a estratégia de Hegel consiste em afirmar que os impulsos naturais já são momentos da vontade livre. Pois não sendo exatamente uma escolha, a liberdade deve aparecer como uma certa forma de reconciliação com o que apareceu inicialmente como causa exterior. Isto explica porque Hegel insistirá:

A vontade inicialmente só livre em si é a vontade imediata ou natural. As
determinações da diferença, que o conceito se determinando a si mesmo põe na
vontade, aparecem na vontade imediata como um conteúdo imediatamente existente
- são impulsos, desejos, inclinações, pelos quais a vontade se acha determinada pela
natureza. Esse conteúdo, junto com as suas determinações desenvolvidas, provém, na
verdade, da racionalidade da vontade e, assim, ele é em si racional, mas, deixado em
tal forma da imediatez, ele não está ainda na forma da racionalidade.

29 No entanto: "se a liberdade deve renunciar a toda heteronomia, toda determinação da vontade por desejos particulares, princípio particular ou autoridade exterior, então a liberdade parece incompatível com toda ação racional, pois não parece restar qualquer motivação para a ação que não seja completamente vazia, ou seja, que efetivamente ordene algumas ações, exclua outras, e que não seja também heterônoma" (TAYLOR, Charles; Hegel e a sociedade moderna, op. cit., p. 104)

30 HEGEL, Enciclopédia, op. cit., par. 474 
Ou seja, impulsos, desejos, inclinações não são limites à liberdade humana, não são elementos irracionais ligados ao que não se submete à minha vontade, como se fosse questão de conservar distinções estritas entre humanitas e animalitas. Eles provém da racionalidade da vontade, eles podem ter uma forma racional. Neste sentido, se Hegel pode dizer que : "Na exigência da purificação dos impulsos reside a representação universal de que eles sejam libertados da forma da sua determinidade natural imediata e do que há de subjetivo e contingente no conteúdo, e, assim, reconduzidos à sua essência substancial"'31, é porque a libertação dos impulsos em relação à forma da sua determinidade natural consiste na revelação de como eles são animados, desde o início, por uma normatividade que não pode ser vista como causalmente fechada. O que não poderia ser diferente já que não há, para Hegel, algo como impulsos meramente naturais. Se é possível quebrar a "violência natural dos impulsos" sem que isto seja necessariamente uma violência ainda maior cujo preço será sempre impagável, é porque não se trata de uma simples repressão.

Tentemos entender melhor este ponto. O impulso, no caso do ser humano, é distinto do que Hegel chama de instinto (der Instinkt), já que instinto é "uma atividade orientada a um fim (Zwecktätigkeit) que age de maneira não consciente (bewustlose)" "32 a partir de uma finalidade interna ao organismo, finalidade esta ligada principalmente à conservação do gênero. Enquanto preso ao comportamento animal, enquanto submetido ao instinto, o impulso aparece apenas como uma atividade (Tätigkeit), uma excitação visando realizar tal finalidade interna. Finalidade que se direciona a algo de determinado, a um objeto específico.

Mas ao passar ao comportamento especificamente humano, esta solidariedade entre instinto e impulso se perde. Aqui, o impulso aparece como uma determinação da vontade (Willensbestimmung) que produz sua própria objetividade, que se dá seu objeto de satisfação (pois não o encontra dado imediatamente pelo instinto). Este produzir é a atividade do Espírito que já se encontra presente nos impulsos. O impulso não é palpitação de uma vitalidade simples, ele não é simplesmente physis, mas conserva uma vitalidade espiritual pois socialmente determinada.

Há uma maneira de compreender tal vitalidade espiritual que pode resolver certas dicotomias. Basta aceitarmos que, ao mobilizar impulsos mobilizo, na verdade, a memória da "história dos desejos desejados", para retomar 
uma bela expressão de Alexandre Kojève ${ }^{33}$. Deixo que atuem, como motivos para minha ação, os desejos desejados que procuraram realizar uma forma de vida bem sucedida e que influenciaram minha formação ${ }^{34}$. Através dos impulsos, desejo, de maneira inicialmente profundamente conflitual, o desejo de outros que me antecederam e que, de uma certa forma, não deixaram de continuar falando em mim. Desta forma, podemos reencontrar assim o problema da relação entre subjetividade e intersubjetividade no coração da relação entre impulso e vontade.

É fato de que, para a consciência, os impulsos naturais são vistos como opacos, negativos, irracionais. No entanto, eles aparecem assim por serem marcas de uma história que se esqueceu, que não é mais visível para a consciência por não ser simplesmente a história do indivíduo. Lembremos, a este respeito, da maneira que Hegel descreve, na capítulo da Fenomenologia do Espírito intitulado "O prazer e a necessidade", o impasse de uma vida orientada pela realização imediata dos impulsos. Trata-se de uma vida que descobre que aquilo que se chama "necessidade" [Notwendigkeit]: "é justamente uma coisa que ninguém sabe dizer o que faz, quais são suas leis determinadas e seu conteúdo positivo. Porque é o conceito absoluto intuído como ser, a relação simples e vazia, mas irresistível e imperturbável, cuja obra é apenas o nada da singularidade" 35 . Neste sentido, os impulsos que se manifestam sob a forma da necessidade, impulsos tomados como normatividade vital imediata, são o nada da singularidade, princípio opaco em suas leis e conteúdos, porque são apenas a indeterminação simples e vazia, puramente negativa. No entanto, a maneira de quebrar esta ilusão de imediaticidade que só pode levar ao colapso consiste em, de uma certa forma, redescobrir a história no interior da natureza. Isto significa mostrar como os impulsos são, na verdade, a parte não-individual da história dos sujeitos, da história dos desejos que lhes precederam, mas que lhes constituíram. Trata-se de reconhecer, nos impulsos, aquilo que foi tecido às nossas costas, tecido pelas mãos da experiência social que continua a agir em nós.

Uma maneira de compreender melhor esta experiência social que continua a agir em nós é através da recondução dos impulsos à sua "essência substancial". Ela nos lembra que a autonomia não pode ser simplesmente a

33 KOJÈVE, Alexandre; Introduction à la lecture de Hegel, Paris : Gallimard, 1947

34 Neste sentido, vale a afirmação de que: "precisamos, para compreender quem age e porque, de perguntar sobre as condições positivas de realização de si, e não apenas, nem mesmo necessariamente, sobre as condições negativas de realização de nossos desejos" (JOUAN, Marlène; Psychologie morale: autonomie, responsabilité et rationalité pratique, Paris: Vrin, 2008, p. 13).

35 HEGEL, Fenomenologia, op. cit., p. 229 
possibilidade de agir de outra forma do que se age, como vemos no modelo que privilegia o livre-arbítrio. Autonomia está profundamente vinculada à capacidade de desejar o que se quer, ou seja, de exprimir na ação a unidade reflexiva de dois momentos: a enunciação consciente da vontade (que leva em conta as exigências morais ligadas à realização de formas intersubjetivas de vida conscientemente assumidas e partilhadas) e o impulso do desejo. Unidade reflexiva entre o desejo que tenho e meu desejo de ter tal desejo. Ou seja, Hegel está a fornecer aqui um conceito alternativo de autonomia, onde ela não é mais pensada através da figura da auto-legislação que cliva o sujeito entre desejo patológico e vontade livre, mas através da capacidade de superar tal clivagem, de compreender a racionalidade do momento heterônomo da vontade $^{36}$.

\section{O risco da atomização social}

A interpretação que sugiro tem ao menos o mérito de mostrar como a autonomia não se afirma sem saber se reconciliar com o que aparece inicialmente como heteronomia e causalidade exterior. Ela ainda insiste no fato do processo de reconciliação com os impulsos naturais fornecer um modo de relação a si que facilita a abertura a um modo de relação social que não pode mais ser visto como mera relação contratual entre vontades individuais. Pois esta maneira de se reconciliar com os impulsos demonstra como a vontade livre não é construída a partir do modelo da vontade individual. Ela é acolhimento do que é não-individual e não-personalizado no sujeito, por isto, ao menos neste caso, acolhimento do que deve necessariamente se manifestar inicialmente como impulso. Ela é modelo de uma abertura à alteridade (uma alteridade que não é simplesmente a figura de outro indivíduo, de outra consciência) a partir da problematização da natureza das relações à si. Sendo assim, seu reconhecimento social deve ser efetivado no interior de um processo onde a vontade se libere de sua dependência estrita à figura do indivíduo.

Caso isto não ocorra, a constituição da autonomia levará à generalização de uma forma de ação incapaz de compreender sistemas de motivações para além do quadro das vontades individuais. Por ter uma compreensão da significação

36 A este respeito, vale a pena lembrar que: "a divisão da moralidade entre razão e inclinação às vezes existe de fato, mas apenas como resultado de um defeito ético que é a desarmonia no sistema de relações sociais no qual cada indivíduo vive e age" (WOOD, Allen; "Hegel's critique of morality", In: SIEP, Ludwig (org.) Grundlinien der Philosophie des Rechts, Berlin: Akademie Verlag, 2005, p. 158) 
da ação ligada à dinâmica de auto-certificação de uma consciência solipsista, tal autonomia, para Hegel, é uma autonomia de indivíduos isolados. Desta forma, as exigências de autonomia se realizam politicamente como valor mobilizado para a justificativa da constituição de uma sociedade de indivíduos onde todas as relações sociais são pensadas sob a forma do contrato: figura maior do acordo negativo (e único acordo possível) entre vontades individuais. Para Hegel, isto significa uma sociedade assombrada por um irreversível processo de atomização social e de desagregação.

Hegelvê como sintomático que autores para os quais a autonomia individual é a pedra de toque da razão prática só sejam capazes de pensar a natureza das relações sócio-políticas a partir da forma do contrato. Ele compreende que a tendência contratualista parte da situação social atomizada de indivíduos portadores de interesses que devem ser restringidos pelos interesses de outros indivíduos. Restrição que, normalmente, legitima-se através da ficção jurídica de um contrato social através do qual conservo interesses possíveis de serem socialmente realizados e abro mão daqueles que não se submetem a esta condição. Ficção que, por sua vez, deve se alimentar da elevação do medo a afeto central do vínculo político (medo da despossessão de meus bens, medo da morte violenta, medo da invasão de minha privacidade etc.). A perspectiva contratualista é indissociável de uma política de perpetuação do medo.

Por outro lado, se o contrato é um momento importante da efetivação da liberdade, já que a propriedade privada é, por sua vez, um momento necessário da vontade que se exterioriza e quer se fazer reconhecer em sua particularidade, a generalização da figura do contrato para a totalidade da vida social é uma distorção e uma patologia. Longe de ser um modelo de coesão social, a metáfora do contrato é a evidência de que estamos diante de uma sociedade em processo de desagregação. O casamento, a relação ao Estado, a relação do pai aos filhos não são contratos. Elas são relações de outra natureza, algo muito diferente do tipo de relação que posso estabelecer com coisas a respeito das quais sou proprietário (como é o caso das relações contratuais) ${ }^{37}$. Quando elas são pensadas sob a forma do contrato, é porque

37 Conhecemos a famosa anedota de Hegel a respeito da noção kantiana do casamento como contrato. Kant define o casamento como uma possessão recíproca de pessoas, um commercium sexuale, ou ainda: "a ligação de duas pessoas, de sexos diferentes, tendo em vista a possessão recíproca, durante toda a vida, de suas qualidades sexuais próprias" (KANT, Doutrina do direito, par. 24). Hegel chamava tal definição de "barbarismo" lembrando que, se o casamento de fato fosse um contrato que me dava a possessão das "qualidades sexuais" do outro, poderia sempre chamar a polícia caso minha mulher ferisse meu direito de propriedade e não consentisse em manter relações sexuais comigo quando eu bem quisesse. Isto apenas demonstrava a completa inadequação da ampliação das relações contratuais de propriedade para a intelecção da natureza das relações intersubjetivas. 
perderam completamente sua substancialidade. Por não saberem se portar no interior da ação social, por terem perdido a coesão social que permite relações concretas de reconhecimento, os sujeitos se apegam à compreensão reificada do comportamento de outros sujeitos como se tratassem de coisas que podem ser postas em cláusulas de um contrato.

Já na sua crítica a Rousseau, esse esquema de interpretação aparece claramente. Lembremos da afirmação de Hegel a respeito de Rousseau:

No entanto, como ele apreendeu a vontade em sua forma determinada como vontade singular (como fez posteriormente Fichte) e como ele apreendeu a vontade geral não como o que a vontade tem de racional em si e para si, mas apenas como o elemento comum que surge desta vontade singular enquanto consciente, a reunião dos indivíduos singulares no Estado se transforma em um contrato ${ }^{38}$.

Deixando de lado a adequação ou não desta leitura, vale a pena notar como Hegel critica Rousseau por pensar a vontade a partir da noção de vontade individual, vontade que não advém exatamente vontade geral, mas vontade comum, ou seja, associação de diversas vontades que não desejam um objeto universal, mas que desejam as condições para a afirmação de seus sistemas particulares de interesses ${ }^{39}$. De fato, como nos lembra Gérard Lebrun ao insistir na "raiz ultra-individualista do contrato", no momento do Contrato social, o homem é ainda "aquele que olha para si mesmo". Seu desejo de adquirir a liberdade civil provém de uma reivindicação que nasce no nível da sua independência natural. Sua entrada na união civil é feita unicamente em nome de seu amor por si mesmo.

Hegel deve fazer esta leitura de um dos teóricos fundamentais da filosofia política moderna porque o filósofo alemão compreende o advento das sociedades modernas de livre-mercado como movimento preso a tal modo de definir as relações sociais. Por isto, tratam-se de sociedades assombradas pelo risco de atomização social. Por "atomização social" devemos entender um processo interno às sociedades civis capitalistas de enfraquecimento da força normativa do vínculo social e de fortalecimento das demandas de decisão em

38 HEGEL, Grundlinien ..., op. cit., par. 130

39 Isto talvez nos explique porque, na justificação do contrato social: "a linguagem de Rousseau com frequência é tão abertamente utilitarista quanto a de Hobbes. Isto é o que você perde, mas avalie, em compensação, o que você ganha” (LEBRUN, Gerard; “Contrato social ou negócio de otário?” In: A filosofia e sua história, São Paulo: Cosac e Naify, 2006, p. 226). Por isto, se aceitamos entrar no contrato social: "é por ter lido, no segundo livro, que as "pessoas privadas" que compõem a "pessoa pública" permanecem "naturalmente independentes dela", que elas continuam portanto a desfrutar um direito natural enquanto homens e que "o Soberano não pode infligir aos súditos nenhuma que seja inútil à comunidade" (idem, p. 230). 
direção aos indivíduos. Hegel descreve uma das facetas deste processo da seguinte forma:

A tendência a buscar dentro de si, voltando-se para o interior, o que é justo e bom, e a sabê-lo e determiná-lo a partir de si, aparece, enquanto configuração mais geral na História (em Sócrates, nos Estóicos, etc.), em épocas em que aquilo que vige na efetividade e nos costumes como justo e como bom não pode satisfazer a uma vontade melhor; quando o mundo existente da liberdade tornou-se infiel a essa vontade, ela não se encontra mais a si mesma nos deveres vigentes e deve procurar obter a harmonia, perdida na efetividade, somente na interioridade ideal ${ }^{40}$.

Como vimos, Hegel sabe que sua época também conhece tal "crise de legitimidade". Sua descrença em relação ao fortalecimento do indivíduo como elemento de contraposição a tal tendência vem, entre outras coisas, da consciência das suas consequências catastróficas no plano sócio-econômico. Pois a atomização social não implica apenas transferência do pólo de decisão sobre a orientação da conduta para os ombros dos indivíduos. Ela implica também um modo atomizado de compreensão da dinâmica da vida social, compreensão da vida social como justaposição de vontades individuais. Fato que não deve nos surpreender já que modelos de reflexão sobre a estrutura do sujeito moral servem, normalmente, como modelos gerais para a compreensão dos modos de ação social a partir de valores e normas. Agimos moralmente da mesma forma que agimos socialmente, ou seja, utilizando a mesma estrutura de julgamento e orientação (esta talvez seja uma das intuições fundamentais de Max Weber em seu estudo sobre a ética protestante).

Sendo assim, podemos dizer que os modelos da autonomia individual e do livre-arbítrio acabam por produzir uma imagem da sociedade como conjunto de normas, instituições e regras capazes de garantir a plena realização dos sistemas particulares de interesses que se orientam a partir de sua própria visão sobre a realização do bem e das riquezas. Hegel é um dos primeiros a compreender que, quando transplantado para a esfera das relações econômicas tal processo produz, necessariamente, pauperização e alienação social. Neste ponto, podemos sentir a importância da leitura hegeliana dos economistas britânicos. Tal leitura fora fundamental para a compreensão hegeliana da complexidade funcional das sociedades modernas.

Esta passagem em direção à economia política é justificada. Como Hegel opera com um conceito de liberdade para o qual a definição das condições sociais de sua efetivação é um problema interno à própria definição do conceito, 
ele deve poder descrever as situações nas quais o funcionamento da vida social não fornece mais os pressupostos para a realização as aspirações, entre outras, da autonomia individual ${ }^{41}$. Um pressuposto fundamental está relacionado ao funcionamento da esfera econômica, base da constituição daquilo que Hegel entende por sociedade civil. Podemos dizer isto porque, para Hegel, problemas de redistribuição e de alienação na esfera econômica do trabalho são um setor decisivo de problemas mais gerais de reconhecimento social.

Neste sentido, por exemplo, processos de pauperização não serão vistos por Hegel apenas como problemas de "justiça social", mas sim como problemas de condições de efetivação da liberdade ${ }^{42}$. Pois não é possível ser livre sendo miserável. Livres escolhas são radicalmente limitadas na pobreza e, por consequência, na subserviência social. Posso ter a ilusão de que, mesmo com restrições, continuo a pensar livremente, a deliberar a partir de meu livrearbítrio individual. Um pouco como o estóico Epiteto, que dizia ser livre mesmo sendo escravo. No entanto, uma liberdade que se reduziu à condição de puro pensamento é simplesmente inefetiva, isto no sentido dela determinar em muito pouco as motivações para o nosso agir.

Partamos, pois, da afirmação do jovem Hegel de que, ao procurar a realização do bem e das riquezas através da referência a seu próprio sistema particular de interesses, inaugura-se o seguinte processo:

Conforme o costume e o modo de vida (Lebensart) mudou, cada [indivíduo] se tornou mais preocupado com suas próprias necessidades e assuntos privados, a maior parte dos homens livres, o estamento burguês propriamente dito, tinha de olhar exclusivamente a suas próprias necessidades e aquisições; [conforme] os estados cresciam, as relações externas se tornaram mais complexas (verwickelter) e aqueles que tinham de lidar exclusivamente com elas se tornaram um estamento e [igualmente] cresciam a quantia de necessidades dos homens livres e nobres (Adels), os quais tinham de se manter em suas posições (Stande) seja pela indústria, seja pelo trabalho [feito] para o estado ${ }^{43}$.

41 Como bem compreendeu Pippin, Hegel : "nega que possamos separar a dimensão moral-psicológica, individual da liberdade (a possibilidade da 'liberdade da vontade') das relações sociais de dependência e de independência compreendidas como igualmente constitutivas da liberdade (a liberdade de agir)" (PIPPIN, Robert; Hegel's practical philosophy: rational agency as ethical life, op. cit., p. 7)

42 A este respeito, vale a pena sempre lembrar a maneira que Hegel justifica o direito de extrema necessidade (Notrecht): "A vida, enquanto conjunto completo dos fins, tem um direito contra o direito abstrato. Se, por ex., pelo furto de um pão ela pode ser prolongada, a propriedade de alguém, com efeito, é lesada pelo furto, mas seria in-justo considerar esta ação um furto ordinário. Não fosse permitido ao homem em perigo de vida proceder assim, de modo a conservar a sua vida, ele seria determinado como desprovido de direitos, e ao recusar-lhe a vida, sua liberdade toda seria negada" (HEGEL, ibidem, par. 127). Ou seja, o problema está totalmente ligado à definição das condições sociais para a realização do conceito de liberdade.

43 HEGEL, Haupt werke - Band 1, Hamburgo : Felxi Meiner, 1999, pp. 532-533 
Ou seja, a sociedade conhece um processo de multiplicação de necessidades e afirmação dos interesses. Da mesma forma que as necessidades se desdobram, os meios para satisfazê-las se multiplicam e se complexifica, criando assim tanto a riqueza, o refinamento, quanto o desenvolvimento e, principalmente, o aprofundando a dependência entre os homens. $\mathrm{O}$ que leva Hegel a afirmar: "Enquanto Dasein real, as necessidades e os meios advém ser para outro através dos quais as necessidades e o trabalho de cada um é reciprocamente condicionado" 44 . Pois meu trabalho advém um meio para a satisfação dos outros, assim como minha satisfação depende do trabalho dos outros. É a isto que Hegel chama de "sistema de necessidades".

No entanto, Hegel insiste que este sistema de necessidades construído através da múltipla dependência dos trabalhos tem como consequência inelutável a divisão do trabalho. Desde sua juventude, Hegel percebe que o desenvolvimento das sociedades modernas de livre mercado exige uma especialização cada vez maior dos trabalhos, fruto da complexificação dos objetos produzidos e da ampliação da produção em larga escala. Hegel sabe que tal processo leva necessariamente à simplificação e à abstração mecânica na esfera do trabalho que, por fim, produz a substituição do homem pela máquina, como vemos no parágrafo 198 dos Princípios da filosofia do direito. Neste sentido, ele é talvez o primeiro a compreender que a mecanização e a automatização são consequências inelutáveis das sociedades modernas. Consequências que produzem um sofrimento social de alienação devido à dependência dos sujeitos a um modo de exteriorização que os mortificam ${ }^{45}$. Ou seja, ao procurar a realização do bem e das riquezas através da referência a seu próprio sistema particular de interesses, ocorre uma modificação fundamental na estrutura do trabalho como espaço de reconhecimento.

No entanto, Hegel reconhece outro problema social grave devido ao modo de organização do trabalho nas sociedades liberais. Ele está indicado no seguinte trecho dos Princípios da filosofia do direito:

Quando a sociedade civil não se encontra impedida em sua eficácia, então em si mesma ela realiza uma progressão de sua população e indústria. Através da

44 Idem, Grundlinien ..., op. cit., par. 192

45 Como vemos na afirmação do Hegel de juventude: "O trabalho se torna tanto mais absolutamente morto, ele se torna trabalho maquinal (Maschinenarbeit), e a habilidade do singular tanto mais infinitamente limitada, e a consciência dos trabalhadores da fábrica é rebaixada ao último embotamento (Stumpfheit)" (GW6, pp.323-4). Por esta e por outras razões, devemos concordar com uma afirmação central de Shlomo Avineri como: "Hegel aceita a visão de Smith para quem, por trás do choque conflitual e desprovido de sentido dos interesses egoístas na sociedade civil, um propósito mais elevado pode ser discernido; mas ele não concorda com a assunção escondida de que todos na sociedade estão potencialmente bem acolhidos" (AVINERI, Shlomo; Hegel's theory of modern state, Cambridge University Press, 1973, p. 148) 
universalização das conexões entre os homens devido a suas necessidades e ao crescimento dos meios de elaboração e transporte destinados a satisfazê-las, cresce, de um lado, a acumulação de fortunas - porque se tira o maior proveito desta dupla universalidade. Da mesma forma, do outro lado, cresce o isolamento e a limitação do trabalho particular e, com isto, a dependência e a extrema necessidade (Not) da classe (Klasse) ligada a este trabalho, a qual se vincula a incapacidade ao sentimento e ao gozo de outras faculdades da sociedade civil, em especial dos proveitos espirituais ${ }^{46}$.

O modo de inserção no universo do trabalho depende, segundo Hegel, de uma relação entre capital e talentos que tenho e que sou capaz de desenvolver. Isto implica não apenas entrada desigual no universo do trabalho, mas também tendência à concentração da circulação de riquezas nas mãos dos que já dispõem de riquezas, assim como o consequente aumento da fratura social e da desvalorização cada vez maior do trabalho submetido à divisão do trabalho. Desta forma, na aurora do século XIX, Hegel é um dos poucos filósofos a se mostrar claramente consciente tanto dos problemas que organizarão o campo da questão social nas sociedades ocidentais a partir de então quanto da real extensão destes problemas. Para ele, esta tendência de aumento das desigualdades e da pauperização, tendência que o leva a afirmar que por mais que a sociedade civil seja rica, ela nunca é suficientemente rica para eliminar a pobreza, é um problema que tem a força de bloquear a possibilidade da efetivação de uma forma de vida regulada pelo conceito de liberdade. Por isto, a reflexão sobre a estrutura das sociedades modernas do trabalho não é externa às reflexões sobre a vontade livre, assim como sobre o destino da noção de liberdade baseada na hipóstase do conceito de autonomia individual.

\section{A eticidade e a dupla função do Estado}

A resposta que Hegel dará contra estes dois riscos de desagregação da vida social impulsionados pela hipóstase de modelos de liberdade baseados na autonomia e a autenticidade passará pelo fortalecimento do Estado. Para que este fortalecimento seja possível sem que ele implique mera violência, algo destes dois modelos deve ser conservado.

Por um lado, o Estado deverá dar um objeto à liberdade negativa, dar uma forma institucional à negação impedindo que os indivíduos se petrifiquem em determinações sociais estanques (como "membro de um estamento", "representante de um interesse de classe"). Isto será apresentado através das considerações hegelianas sobre a guerra. Através da guerra, o Estado 
completará um intrincado processo de formação das individualidades através da internalização do caráter formador da experiência da negatividade da morte. Este é um tema recorrente em Hegel e podemos encontrá-lo, por exemplo, na Fenomenologia do Espírito, à ocasião da compreensão do confrontar-se com a morte como ir em direção ao fundamento da existência ${ }^{47}$. Se voltarmos à outro momento da Fenomenologia, este dedicado à seção "Espírito", encontraremos colocações como:

Para não deixar que os indivíduos se enraízem e endureçam nesse isolar-se e que, desta forma, o todo se desagregue e o espírito se evapore, o governo deve, de tempos em tempos, sacudi-los em seu íntimo pelas guerras e com isso lhes ferir e perturbar a ordem rotineira e o direito à independência. Quanto aos indivíduos, que afundados nessa rotina e direito se desprendem do todo aspiram ao ser para-si inviolável e à segurança da pessoa, o governo, no trabalho que lhes impõe, deve dar-lhes a sentir seu senhor: a morte. Por essa dissolução da forma da subsistência, o espírito impede o soçobrar do Dasein ético no natural, preserva o Si de sua consciência e o eleva à liberdade e à força. A essência negativa se mostra como a potência peculiar da comunidade e como a força de sua autoconservação ${ }^{48}$.

Podemos afirmar que, se o governo não repousa sobre uma promessa de paz, é porque o processo de formação, que se iniciou na família, deve animar os processos de interação social enquanto meios para a realização da subjetividade como universalidade desprovida de toda aderência ao Dasein natural, enquanto o que se realiza através de um trabalho que é confrontação com a fragilização das imagens estáticas do mundo.

Notemos que esta guerra da qual fala Hegel não é a explosão de ódio resultante da lesão da propriedade particular ou do dano a mim enquanto indivíduo particular. A guerra é campo de "sacrifício do singular ao universal enquanto risco aceito"49. Se na Grécia, tal guerra era, de fato, movimento presente na vida ética do povo, já que o fazer a guerra era condição exigida de todo cidadão, não deixa de ser verdade que Hegel concebe aqui o estado como o que dissolve a segurança e a fixidez das determinações finitas. A guerra é o nome do processo que demonstra como a aniquilação do finito é modo de manifestação de sua essência. Neste sentido, Hegel é bastante claro, há:

47 Discuti este ponto em SAFATLE, Vladimir; O amor é mais frio que a morte : negatividade, infinitude e indeterminação na teoria hegeliana do desejo, op. cit.

48 HEGEL, ibidem, p. 455

49 SOUCHE-DAGUES, Liberté et négativité dans la pensée politique de Hegel, Paris : Vrin, 1997, p. 26. Lembremos ainda que : « ao abalar a segurança e a fixidez das determinações finitas, a guerra as infinitiza. Sua aniquilação é a manifestação de sua essência. Esta dupla apresentação da guerra é conforme a dupla apresentação da negação e do infinito. A guerra como pura aniquilação, nivelamento destrutivo é dirigida contra a materialidade do finito; a guerra que se produz no seio da vida ética é o elemento no qual esta vida adquire sua essência espiritual infinita" (idem, p. 28) 
um momento ético da guerra, que não deve ser considerada como um mal absoluto e como uma contingência simplesmente exterior (...) é necessário que o finito, a possessão e a vida sejam postos como contingentes, pois este é o conceito do finito (...) A guerra, enquanto situação na qual levamos a sério a vaidade dos bens e das coisas deste mundo é assim o momento no qual a idealidade do particular recebe seu direito e advém efetividade ${ }^{50}$.

Não se trata aqui de fazer a apologia do estado belicista, mas de procurar, para além de sua enunciação literal, a função efetiva de tais colocações. De fato, a hipótese que gostaria de defender consiste em afirmar que tais colocações sobre a guerra dizem muito a respeito da configuração necessária de instituições e práticas sociais que queiram estar à altura das exigências da modernidade. O que é importante nesta reflexão sobre a guerra é a compreensão de que instituições que queiram ser capazes de reconhecer sujeitos não substanciais devem fundar-se em práticas sociais pensadas a partir de um trabalho que é reconhecimento da soberania de uma figura da negação cuja manifestação fenomenológica pode ser uma certa morte simbólica. Trata-se da figura de instituições sociais que não tenham mais por função identificar sujeitos em identidades e determinações fixas. Há várias formas de se pensar tal processo sem precisar passar por esta apologia hegeliana da guerra, certamente questionável e dificilmente defensável, não apenas nas condições atuais, mas já em sua época. Por isto, para além da enunciação literal, devemos saber como recuperar tal motivo que, no fundo, expõe a relação necessária entre negatividade e Estado.

Se o problema das exigências de autenticidade pode ser regulado desta forma, o problema da autonomia exigirá, por sua vez, um Estado que forneça as condições sociais para a autonomia reencontrar-se nos sistemas sociais de julgamento. Isto nós vemos no interior das considerações hegelianas sobre a eticidade. Ela deve fornecer a estrutura institucional para que as aspirações individuais de autonomia sejam efetivadas. Tal estrutura engloba, inclusive, a obrigação estatal de lutar contra a fratura social inerente ao funcionamento da sociedade civil no interior da dinâmica capitalista de desenvolvimento. A vida ética não é indiferente à questão social, à obrigação de institucionalização de políticas de combate à pauperização (consequência que podemos derivar da Filosofia do direito, mesmo que ela não esteja descrita na obra). No entanto, devemos analisar melhor o tipo de consolidação de costumes e modos de julgamento que a noção de "eticidade" aplicada à vida moderna pode ser capaz de garantir. 
Notemos apenas que o Estado moderno tem uma dupla função aparentemente contraditória. Ele deve acolher a experiência de indeterminação que habita as individualidades e ele deve fornecer as determinações necessárias para a efetivação da autonomia através da constituição de um conjunto de leis positivas universalizáveis. Ele fornece um conjunto de regras sociais, assim como fornece o modo de expressão daquilo que, nos sujeitos, é refratário à determinação no interior de regras sociais. Ele, ao mesmo tempo, cria instituições e gere a indeterminação. Para ser mais claro, para Hegel, o Estado é uma instituição capaz de gerir a indeterminação, de superá-la sem simplesmente negá-la.

Tendo em vista estes dois pontos, podemos começar a compreender porque Hegel deve criticar a concepção liberal de Estado, esta que o compreende como instituição responsável pela garantia do funcionamento dos princípios internos à sociedade civil, como o direito de propriedade, o respeito dos contratos e as liberdades individuais. Embora saiba acolher tais exigências no seu interior, o Estado não se resume a tal função subalterna. Ele deve realizar o que a sociedade civil não é capaz de realizar (como políticas de redistribuição que permitam dar realidade às demandas sócias de reconhecimento) e, principalmente, deve retirar os sujeitos de sua completa imersão na mera condição de indivíduos providos de sistemas particulares de interesses. De uma certa forma, o Estado des-individualiza os sujeitos. No entanto, esta desindividualizacao é condição para a liberdade, pois é possibilidade de abertura do sujeito para algo mais do que a forma isolada e atomizada do indivíduo. Pois Hegel sabe que podemos sofrer por não sermos um indivíduo, ou seja, por não termos conseguido nos realizado como individualidade capaz de se fazer reconhecer no interior da vida social. No entanto, podemos sofrer também por ser apenas um indivíduo, um sofrimento que ganha a forma do isolamento, do esvaziamento e incapacidade de se orientar no interior da ação social.

A partir disto, podemos entender uma das ideia mais importantes da filosofia hegeliana do direito. Se, em vários momentos, ele é capaz de dizer que o interesse particular não deve ser oprimido (unterdrückt) mas posto em concordância com o universal, é porque:

Os indivíduos que compõem a multitude (Menge) são eles mesmos de natureza espiritual e contém, em si mesmos, o duplo momento do extremo da singularidade que sabe e que quer para si e o extremo da universalidade que sabe e quer o substancial, e consequentemente eles só alcançam o direito próprio a estes dois aspectos na medida que eles são efetivos tanto quanto pessoas privadas quanto pessoas substanciais ${ }^{51}$. 
Esta é uma colocação decisiva. Ela consiste em nos lembrar que o conflito entre particularidade e universalidade não é um conflito entre indivíduo e Estado (como está pressuposto na afirmação de Adorno logo no início deste texto), mas um conflito no interior da própria noção de individualidade. Ele é interno a cada individualidade, por isto o Estado pode aparecer como uma superação capaz de conservar as individualidades. A relação ao Estado é, para Hegel, de uma certa forma, uma relação da individualidade para consigo mesmo, uma relação interna que ganha exterioridade.

Por ter o momento da substancialidade em seu interior, os indivíduos realizam algo fundamental de sua vontade através da produção de instituições e leis (leis que, por sua vez, encontram na constituição sua realização mais bem acabada). Isto já está preparado pela maneira que os indivíduos são produzidos através da relação a instituições normativas como a família e a sociedade civil. Assim, a passagem em direção às instituições estatais servese dos processos já colocados em circulação nas outras duas esferas da vida ética. Isto é o que podemos chamar de "institucionalismo forte" hegeliano, ou seja, a ideia de que mesmo as relações a si substanciais devem encontrar sua efetivação através da constituição de estruturas institucionais visíveis e atuantes no interior da vida social.

No entanto, aqui talvez seja o momento de finalizar colocando a questão sobre o que pode uma instituição. Normalmente, compreendemos instituições como estruturas fortemente normativas e disciplinares que perpetuam modos claramente definidos de funcionamento da vida social. Tal força normativa estaria vinculada à reprodução material de formas hegemônicas de vida e de valores, assim como ao bloqueio no desenvolvimento de formas e valores alternativos. Mas é bem possível que possamos conservar os aspectos essenciais da teoria hegeliana do Estado ao insistir que instituições podem ser modos de gestão de conflitos sobre normas e valores. Mesmo que esta não seja a formulação exata que encontramos nos textos hegelianos, é muito provável que ela dê conta do modo de conservação da temática hegeliana na reflexão sobre os desafios de uma teoria contemporânea do Estado.

Sabemos que há, por um lado, leis normativas e, por outro, leis que procuram criar quadros institucionais para a politização de conflitos sobre valores e normas. Tais "leis de segunda ordem" nos ensinam que não precisamos estar de acordo sobre valores fundamentais. Devemos estar de acordo sobre formas de politização de conflito sobre valores, o que é algo totalmente diferente.

Quando Hegel funda o Estado na dimensão da eticidade, agimos como se esquecêssemos que a eticidade moderna não pode guardar relações com 
a eticidade antiga, própria às relações substanciais da polis grega e das primeiras comunidades cristãs baseadas no amor. Pois a eticidade moderna é profundamente conflitual, ela é a sedimentação social de uma larga história de conflitos a respeito de conceitos que organizam nossa forma de vida, como "liberdade", "autonomia", "bem comum", entre outros. Da mesma forma, a história do Espírito é, no fundo, a história de conflitos. Deveríamos pensar nisto quando nos perguntamos sobre o que podemos esperar do Estado moderno, ao menos segundo Hegel. Pois isto pode nos demonstrar como $o$ Estado moderno, segundo Hegel, nasce como a tentativa de criação de um modo de institucionalização de conflitos sobre valores.

Digamos que o Estado moderno deveria ser capaz de atualizar a história do Espírito, isto no sentido de fazer com que todo embate em torno de valores fosse a ressonância de embates anteriores. Desta forma, os sujeitos políticos poderiam ter, no interior dos embates sociais, uma densidade histórica que faz deles modos de atualização de um passado que nunca passou completamente. Assim, enquanto sujeitos políticos os sujeitos podem re-encontrar uma certa experiência da infinitude que tem na atualização temporal da história seu solo.

Notemos finalmente que tal institucionalização que o Estado moderno permitiria seria a condição para a produção de normatividades sociais de baixo potencial prescritivo, mas que tem a força de garantir a coesão social. Tais normatividades são "de baixo potencial prescritivo" por não dizerem exatamente o que devo fazer, como devo interpretar valores, mas como devo negociar tanto as interpretações que procuro defender quanto a legitimidade do que quero fazer. Uma condição decisiva desta negociação consiste em compreender que a transformação em sujeito político implica capacidade de transformação dos gestos políticos em manifestação de uma multiplicidade trans-individual de desejos. A este respeito, a boa questão talvez seja : duzentos anos depois, conseguimos pensar uma ideia reguladora melhor para a orientação de nossas lutas políticas? Podemos, de fato, abrir mão da luta por um modelo de Estado desta natureza?

\section{Referências bibliográficas}

ADORNO, Theodor; Negative Dialektik, Frankfurt: Suhrkamp, 1973

ARANTES, Paulo; Ressentimento da dialética, São Paulo: Paz e Terra, 1996

AVINERI, Shlomo; Hegel's theory of modern state, Cambridge University Press, 1973

FLEISCHMANN, Eugène; La philosophie politique de Hegel, Paris : Gallimard, 1992 FREUD, Sigmund; Das Unbehagen in der Kultur, In: Gesammelte Werke, Frankfurt: Fischer, 1999 
HEGEL, G.W.F. ; Fenomenologia do Espírito, Petrópolis: Vozes, 1991, ; Grundlinien der Philosophie des Rechts, Frankfurt : Suhrkamp, 1986 ; Hauptwerke - Band 1, Hamburgo : Felix Meiner, 1999 ; Jenaer Philosophie der Geistes, Freiburg : Karl Alber Verlag, 1979 ; Vorlesungen über die Philosophie der Geschichte, Frankfurt : Suhrkamp, 1986 HONNETH, Axel; Sofrimento de indeterminação, São Paulo : Esfera Pública, 2006, JOUAN, Marlène; Psychologie morale: autonomie, responsabilité et rationalité pratique, Paris: Vrin, 2008

KOJĖVE, Alexandre; Introduction à la lecture de Hegel, Paris : Gallimard, 1947

LEBRUN, Gerard; "Contrato social ou negócio de otário?" In: A filosofia e sua história, São Paulo: Cosac e Naify, 2006

LOSURDO, Domenico, Hegel, Marx e a tradição liberal, São Paulo : Unesp, 1997

MÜLLER, Marcos; A liberdade absoluta entre a crítica à representação e o terror, mimeo

PIPPIN, Robert; Hegel's practical philosophy: rational agency as ethical life, Cambridge University Press, 2008

RITTER, Joachim; Hegel et la révolution française, Paris : Beauchesne, 1970

SAFATLE, Vladimir; $O$ duplo fundamento insuficiente da ação moral, In: NOVAES, Adauto; A experiência do pensamento, Rio de Janeiro: Agir, 2010

SARTRE, Jean-Paul; Situations philosophiques, Paris: Gallimard, 1990

SEARLE, John; Intencionalidade, São Paulo : Martins Fontes, 2002

SCHNEEWIND, J. B.; A invenção da autonomia, São Leopoldo: Unisinos, 2005

SOUCHE-DAGUES, Denise ; Liberté et négativité dans la pensée politique de Hegel, Paris : Vrin,

TAYLOR, Charles; Hegel e a sociedade moderna, Belo Horizonte: Loyola, 2005

WEBER, Max; Ensaios de sociologia, 5 ed., São Paulo: LTC, 2002

WILLIAMS, Bernard; Moral luck, Cambridge University Press, 1991

WOOD, Allen; "Hegel's critique of morality", In: SIEP, Ludwig (org.) Grundlinien der Philosophie dês Rechts, Berlin: Akademie Verlag, 2005

ZIZEK, Slavoj; Robespierre: virtude e terror, Rio de Janeiro: Jorge Zahar, 2008 